\title{
Building Operation and Maintenance: A Framework for Simplified Building Information Modeling (BIM) Digital Mobile Application
}

\author{
https://doi.org/10.3991/ijim.v15i20.23753 \\ Azlan Shah Ali ${ }^{(凶)}$, Norhanim Zakaria, Umi Kalsum Zolkafli@ Zulkifly \\ University of Malaya, Kuala Lumpur, Malaysia \\ asafab@um.edu.my
}

\begin{abstract}
The introduction of Building Information Modeling (BIM) as a tool for facilitating information and knowledge sharing through digital representation of the physical and functional characteristics of a facility has seen wide application in the construction industry, spanning over the entire life cycle of a facility. However, the current BIM rather complex and requires a huge amount of data to develop. This study therefore aims to investigate the implementation of BIM for Operation and Maintenance Management (O\&M) in Malaysia by identifying the information that should be prioritized to enable BIM mobile application at O\&M phase. Three (3) rounds of expert discussion using Delphi techniques were carried out with 10 to 15 selected experts in O\&M and BIM. Most of the experts agreed that technology could improve the efficiency of service delivery and interested in implementing BIM in O\&M practices. Simplified BIM for O\&M that consists of the critical information includes location, dimension asset information, asset capacity, specification, manufacturer, statutory, condition and cost was developed. All this information was systematically organized in a data matrix. Majority of the stakeholders agreed that the Simplified BIM system is useful, flexible, least complex, and effective in managing and monitoring maintenance operations of their building.
\end{abstract}

Keywords-BIM, operation and maintenance, mobile application software, existing building

\section{Introduction}

Fourth Industrial Revolution participation by Malaysia is allowing the industry to make full use of Artificial Intelligence (AI), robotics, Virtual Reality (VR), big data analytics, the Internet of Things (IoT), and software engineering, leading to higher digital adoption. Through observation for the past 20 years, the Malaysian construction industry has been going through digitalisation in improving the built assets delivery. In order to achieve better service delivery, the use of digital technologies (DTs) that includes the Fourth Industrial Revolution (4IR) had been introduced widely. Through the adoption this technologies advancement, industries are in the process of production process digital transformation of their services and delivery $[1,2]$. The digitalisation 
transformation could be crucial in the three major phases of construction projects, which are the design and engineering, construction, and operation phases $[3,4]$. The main concern of O\&M is to efficiently support the asset life cycle through maximizing system operation, preventing unplanned shutdowns, as well as optimising life-cycle costs. In addition, [5] mentioned that BIM helps enhance procedure that influences information to analyse and forecast outcomes during various phases of the building life cycle. Hence, it benefits the building owner in managing and maintaining the property to ensure the building is functioning effectively. The efficiency of the O\&M process is expected to increase with the availability of an integrated digital database [6].

Building condition assessment (BCA) is based on ratings on building condition and defect inspection using the Building Assessment Rating System developed by the Public Works Department of Malaysia. The BCA system is guided by the assessment of the condition to the building using numerical scores ( 1 to 5 ) and priorities in the repair process. The assessment by the surveyor or inspector on the condition and priority on the defects found is based on expert evaluation during the building inspection and is mentioned in Tables 1, $2 \&$ 3. Generally, a lot of the latest information on the building will be collected. This includes architectural, civil, mechanical and electrical information. Large data collection is required to ensure that the results of the building condition assessment are accurate and reflect the actual condition of a building. An assessment of the current condition of a building is also a process to determine the appropriate maintenance work for a building. O\&M is a crucial stage in the asset or building life cycle to ensure its efficiency. O\&M's cost is one of the fractions of building life-cycle costs, and it acquires $60 \%$ of the total cost $[7,8]$. The majority of the building life-cycle cost is spent during the O\&M stage, which raises a major concern for the stakeholders. Thus, the effort to optimise the use of any resources to ensure cost-saving, efficiency, and effectiveness of the building operation and maintenance are critical to be adopted. BIM has ability in providing a platform for facilities managers to manage building information in a digitalized 3D environment. This provides an opportunity to advance and transform facilities O\&M [9]. In the local context, the mobile application of BIM during post-construction (O\&M), particularly for existing buildings, is not widely adopted. Research on the implementation of BIM in the O\&M stage is scarce, especially in developing countries, Malaysia. Therefore, this paper presents the Simplified BIM by identifying the information that should be prioritized to enable BIM mobile application at O\&M phase. This includes identification of critical information that should be prioritised, collected, stored, utilized and shared in BIM model. In addition, the gathered information would be used in developing an implementation framework for simplified BIM that covers on structured implementation plan or best practices on how BIM can be applied to improve O\&M tasks.

\section{Operation and maintenance $(O \& M)$}

Maintenance is defined by BS 3811 as the combination of any actions objectively to keep and maintain an item towards its acceptable condition. The operation and 
maintenance (O\&M) stage are where the asset is being used to the intended service required and daily running; thus, the management activities are critical to ensure proper use of the asset at this stage (refer to Figure 1). O\&M of assets covers a wide range of services and expertise for the built environment to efficiently perform its intended function [10]. According to [9], maintenance and repair, emergency management, and energy management are the activities included under operations and maintenance of building facilities. Besides, maintenance and upgrade works are also expected to be provided at this stage, complying with the asset's maintenance routine [11].

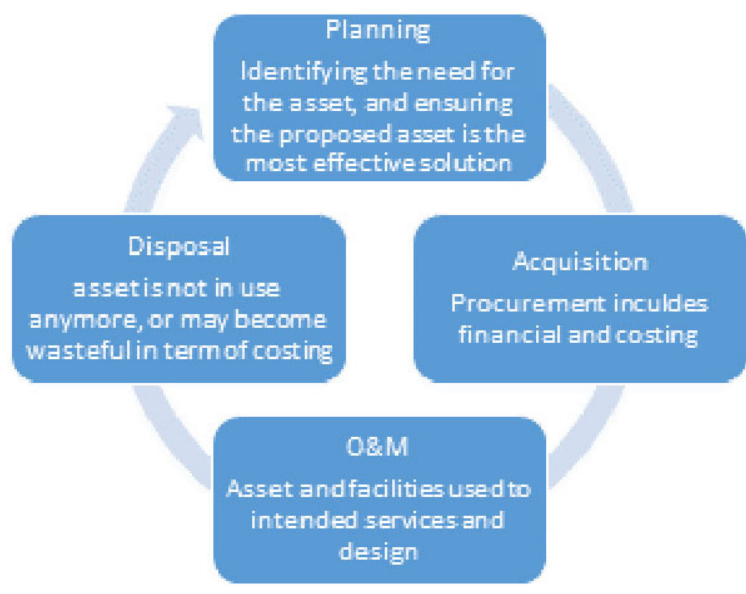

Fig. 1. The asset management lifecycle (adapted from [11])

\section{Data gathering-building condition assessment (BCA)}

BCA is a method of condition inspection for a building for the purpose of getting the overall scoring for building condition. A guideline has been issued by the Public Works Department (JKR) Malaysia for the implementation of this method. This building inspection approach is not limited to contemporary but can also be applied to heritage buildings. BCA collects all data regarding the physical condition of a building performed by a qualified surveyor or building inspector. This covers all disciplines of building, namely architecture, civil, mechanical and electrical. Apart from knowing the score for a building, this method is also used in the decision-making process regarding the maintenance plan. Data obtained from the BCA method can assist in determining the financial allocation for future maintenance work. BCA assessment is generally an assessment of the condition and priority of improvements that need to be implemented. The score from the calculation will give a conclusion as stated in the score matrix as in Table 3. 
Table 1. Condition assessment

\begin{tabular}{|l|l|l|}
\hline \multicolumn{2}{|c|}{ Condition Assessment } \\
\hline \multicolumn{1}{|c|}{ Condition } & \multicolumn{1}{|c|}{ Scale } & \multicolumn{1}{c|}{ Description } \\
\hline 1 & Like New & Minor Maintenance \\
\hline 2 & Fair & Minor Repair \\
\hline 3 & Poor & Replacement/Major Repair \\
\hline 4 & Very Poor & Replacement/Not Functioning \\
\hline 5 & Dilapidated & Damage/Missing \\
\hline
\end{tabular}

Table 2. Priority assessment

\begin{tabular}{|l|l|l|}
\hline \multicolumn{1}{|c|}{ Priority } & Scale & \multicolumn{1}{c|}{ Priority Assessment } \\
\hline Normal & 1 & Fescription \\
\hline Routine & 2 & Minor defect that could lead to major if no action taken \\
\hline Immediate & 3 & Major defect, not achieved the intended functions \\
\hline Emergency & 4 & $\begin{array}{l}\text { Element not functioning or high-risk defect that could lead to serious injuries } \\
\text { to building users }\end{array}$ \\
\hline
\end{tabular}

Table 3. Assessment matrix

\begin{tabular}{|l|l|c|}
\hline \multicolumn{1}{|c|}{ No } & \multicolumn{1}{|c|}{ Description (Matrix) } & Score \\
\hline 1 & Scheduled Maintenance & $1-4$ \\
\hline 2 & Condition Monitoring & $5-12$ \\
\hline 3 & Need Close Observation & $13-20$ \\
\hline
\end{tabular}

Generally, a large amount of data can be collected through the BCA method. Among the types of data that can be collected are measurements, physical conditions, types of materials and specifications of building elements and components. This type of data is very useful if it can be digitized so that easy to be stored and referenced when needed. BIM is seen as an application method that can meet those needs by storing all available data in 3-dimensional form for easy reference in the future.

\section{Type of information in BIM mobile application}

The type of information in BIM involves graphical data, non-graphical data, and documents (refer to Figure 2). Graphical data is the virtual building model, either in $2 \mathrm{D}$ or $3 \mathrm{D}$, visualized the asset or building references, locations and context, and the relationship between rooms, spaces, and components. The non-graphical data play a vital role in building information modelling, as not just to visualize, the model acts 
as the package to contain a project's information. This information is known as the non-graphical data and documents of information [12,13]. It is a norm that a building can contain at least hundreds of systems, items, components, materials, or even products, and in which each of these lists come with a lot of information. To organize this information, BIM associates and incorporates this massive information readable through information model, no longer through hard copies of information [14]. Documents refer to most BIM information, which required a well, standardized, and indexed arrangement that can be stored in an accessible digital system [15].

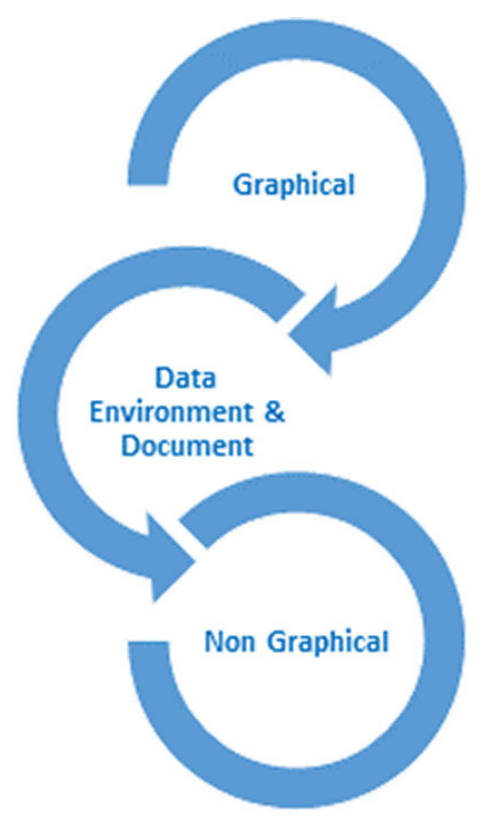

Fig. 2. The link between graphical data and non-graphical

\subsection{BIM level of detail (LOD)}

The BIM standard of PAS1192 helps to identify how much the graphical detail is necessary at every stage of the project, called Level of Detail (LOD). Apart from BIM Dimension, there is a Level of Details of BIM, comprised of Level of Development and Level of Information. The Level of Developments is the levels of clarity of the BIM content at different building life cycle levels, from design until the as-built phase $[15,16]$. There are six (6) levels of LOD, namely LOD100, LOD200, LOD300, LOD350, LOD400, and LOD500. 


\subsection{BIM level of information (LOI)}

The Level of Information (LOI) defines the non-graphical content of a model as a project's defined stages (Montague, 2016). The non-graphical increases as the project develops. Five levels of LOI are LOI1, LOI2, LOI3, LOI4, and LOI5:

i) LOI1 - Concept Stage (a simple description based on the design intent outlined)

ii) LOI2-Design stage (indicate the specified deliverable from the overall performance)

iii) LOI3 - Technical stage

iv) LOI4 - Construction stage

v) LOI5-Operation \& Maintenance stage (the key properties to be transferred into an asset database that prescribed generic products meeting the desired requirements for overall performance)

\subsection{O\&M assets and elements}

[9] suggests that necessary information required to be transferred into BIM is based on O\&M's main activities and further explains six main activities include maintenance and repair, emergency management, energy management, relocation management, security and general information of O\&M. However, despite looking at the main activities of O\&M, BIM or information model of a facility should contain one full or multiple designed model files that integrate information related to the systems such as space information in architectural, and elements information such as mechanical, electrical, plumbing or piping, and be presented in CDE as a single model of the asset $[17,18]$. The information developed according to the inventory of building and elements systems is considered more structured and thorough. Thus, a list of O\&M assets and existing building needs to be identified according to i.e. superstructure and substructure such as the architectural or structural, mechanical and electrical systems as the initial process to enable an integrated BIM mobile application. In this study, the manual or guidelines on the specification of building assets or mechanical and electrical systems provided by the Department of Public Works Malaysia are used as the main reference for elements' inventory. Piling, diaphragm wall, work below lowest floor finish are the elements for substructures. In addition, frame, roof, staircase, firefighting systems, and surveillance installation systems are examples of the building elements.

\subsection{Simplified building information modeling (Simplified BIM)-a digital mobile application}

Simplified BIM offers basic model that can be used by the stakeholders in managing important O\&M data for their buildings. Simplified BIM only consider the O\&M information that is critical and required for every element and item in existing buildings to be enabled BIM functions at the O\&M phase. The BIM mobile application at the O\&M phase contains information such as spatial dimensions and geometry, assets and its locations, characteristics of the building components such as walls, floors, and ceiling. Schedules and operational costs, which are BIM 4-Dimension and BIM 
5-Dimension, are also necessary information for BIM in operation and maintenance. According to [19], in a normal circumstance, the following lists of information are needed for the BIM model:

i) Rooms/spaces

ii) Zones/departments

iii) Systems or assemblies

iv) Components or equipment

v) Products/materials

vi) Maintenance tasks, spare parts, and tools/resources required to maintain and operate the building

vii) Contact details or people involved in the project

viii) Documents related to the project, building, materials, products, and systems

Documents refer to the source of BIM information. Through the NBS, [13] listed the standard documents and information required for a project, from design to facility management stage:

- Client brief and technical requirements

- Appointments and contracts

- Bonds and insurances

- Project stage reports

- Technical reports i.e. the planning, design, environmental impact assessment reports

- Analysis, assessments and calculations

- Sustainability certification

- Surveys

- Meeting minutes

- Project file notes

- Request for information (RFI's)

- Method statements

- Correspondence

- Media such as related photographs, images, presentations or videos

- Regulatory application or submissions of fire safety or disability access

- Non-statutory application or submission

- Tendering procedures

- Models

- Design, construction and as-built drawings, specifications, schedules and data sheets

- Cost plans and bills of quantities

- Payment certificates

- Contracts final accounts

- Project plans and programs

- Technical submittals and approvals

- Health and safety risk assessments and safety plans

- Compliancy specification, certificates or opinions

- Inspection plans and records

- Quality control procedure

- Details on systems, equipment, materials and products [13] 
The complexity of ordinary BIM requires large number of resources to support the needs of model development. Hence, the identification of important and useful data is important to ensure the model are efficient and fully utilised during implementation. The classification of LOD of every item based on available critical information would be the final analysis of this study.

[20] defines mobile application as the small software designed to run mobile device with required functionality, services, and experiences. The use of mobile applications significantly grows for the past 10 years in line with the used of mobile cellular. For instance, the statistics of mobile cellular subscriptions in the world has been increasing from 4.63 billion to 7.98 billion in 2019 [21]. The growing number proves that mobile device is becoming one of the essentials gadgets for everyone. The growing importance of mobile application, provide impetus to develop varies mobile applications in assisting human works.

\section{$5 \quad$ Methodology}

This study adopted qualitative method which consists of Focus Group Discussion (FGD) and a case study for verification. Figure 3 shows the flow of data collection process developed for this study. It began with a literature review to develop a draft theoretical framework. The process followed by the recruitment of focus group participants for data collection process. FGD is necessary for the researcher to obtain more in-depth information on how BIM in O\&M being implemented in the industry [22]. There are three (3) phases of FGD, and each conducted with a specific objective to achieve the research aim. Non-probability sampling is used; the experts were selected based on specific criteria which were the practitioners in BIM or involved in O\&M of buildings.

Objective of FGD 1 is to get feedback on the draft conceptual framework developed based on literature reviews (variables and integration between O\&M and BIM). Objective of FGD 2 to get feedback on the critical information that needs to be included in the BIM simplified model and it involves 4 stages, (1) confirming or agreement on the developed theoretical framework and the critical information, (2) identifies more information that was considered necessary by experts based on their real-world practice experiences, (3) focuses on electrical and mechanical components and (4) identifying the source of the critical information. While objective of FGD 3 is to validate the simplified BIM model and matrix data developed.

An office tower in Kuala Lumpur was selected as a case study. Part of the building has been used to validate the framework developed. Archived document in form of plans and specifications were gathered. Inspection on-site had also been carried out used BCA method to suffice the information needed. Data collected from various sources were filtered and compiled in the form of matrix data (excel sheet). In parallel, the model was developed in the REVIT software, and the matrix data was merged manually into the model. 


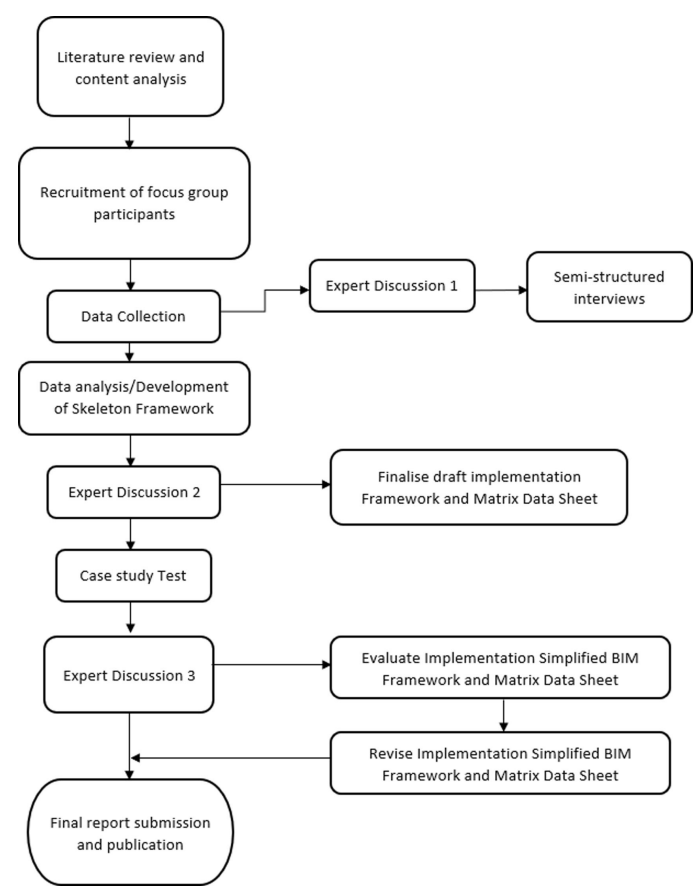

Fig. 3. Data collection process

\section{$6 \quad$ Result and discussion}

Data obtained from the 3 series of FGD and a case study were analysed using thematic and descriptive analyses. Cost and efficiency are considered as the primary constructs that need to be focused on O\&M performance. Many of the experts agree that technology could improve the efficiency of service delivery and interested to implement BIM in O\&M practice. Technology used should be simplified with reasonable start-up cost, the important data that need to be included in the simplified BIM model, compatible with the building needs, start-up cost should be minimum and allowed for future improvement; and system should be sustainable, which allowed for future expansion. However, barriers or challenges that possibly encountered could be client support, initial cost that need to be spent and return on investment (ROI). An Implementation framework was developed as the preliminary result found based on the systematic extraction process to identify the O\&M critical information for BIM towards the classification of BIM Level of Detail (LOD and LOI). For BIM at the O\&M stage, both graphical and non-graphical data are expected to be provided for a model shown under BIM type of data. O\&M assets and elements precede the process. It is related to the essential 
system of substructures and superstructures, i.e. architectural or structural, mechanical and electrical, and every system's items. After developing a list of substructure and superstructures, the clarity of BIM information needs to be identified according to the necessary O\&M type of information. The critical information can be extracted based on the level of development (LOD) fundamental theory.

Referring to the O\&M type of information phase, width, depth, height, or the size is among the necessary information that required starting from LOD 200 [15]. This information is categorised as dimension. Specification is the information required, especially at facilities management phase or the 7 th dimension of data linked to the model $[13,16]$. Specification information such as type, material and installation method is required at LOD 400 [15]. Similar to specification, information on manufacturers such as the detail information and purchase date is also required at the 7 th dimension of data and begins at LOD $400[15,23]$.

Condition of the assets is the information required for O\&M stage based on inspection data gathered [24]. Based on the review analysis on BIM mobile application, the condition is not listed as a piece of information required. However, the condition is found as necessary as it is considered as one of the important activities for O\&M [9]. Thus, for the detail's information on condition, this study has referred to the building condition assessment manual, the Code of Practice for Building Inspection Reports (CP BS101). There is five information related to the building condition, which is new or good, fair, poor, very poor and dilapidated [25]. New or good is referring to the assets and elements that required minor servicing. Fair is for the assets and elements that required minor repair. Poor is referring to the assets and elements that required major repair or replacement. Very poor is when the assets and elements are malfunctions and finally dilapidated described damaged or missing assets or elements [25]. Cost is the fifth information required to enable BIM at O\&M stage. Cost is the non-graphical information for BIM, and cost for O\&M is one of the fractions of building life cycle cost. It is important information on both sides of BIM and O\&M. Information on cost consists initial, maintenance, disposal or demolition, overhead and the residual or scape cost [7]. Source of information is the next stage of the research, simultaneously to achieve Objective 2 of the research. It is referring to the source of the critical information (Dimension, Specification, Manufacturer, Cost and Condition) can be collected. Especially for an existing building, if the data to fulfil every Level of Details (LOD) is scattered or not exist. The classification of LOD will be the final analysis of this research, to classify the LOD of every item based on available critical information. As this research is focusing on O\&M stage, LOI5 will be referred as this level of information covers the key properties to be transferred into an asset database, as well as the prescribed generic products that meet the desired overall performance requirements.

Figure 4 shows the finalised implementation framework of the Simplified BIM model for the O\&M digital mobile application based on feedback gathered from the respondents. In the process of developing the simplified BIM model, the data matrix was predevelop based on this finalised implementation framework. Data matrix 
function to organise the data systematically (refer to Figure 5). The data matrix contains the information on O\&M elements and items (x-axis); and O\&M type of information (y-axis). Data collected from the case study come from various sources (ex: the contract document, drawings) were filtered and compiled in this matrix (excel sheet). In parallel, the model was developed in the REVIT software, and the data was later merged manually into the model. Figure 6 shows the simplified BIM Model Digital Mobile Application for the O\&M.

The data was displayed in two (2) levels of details in BIM for the O\&M mobile application. Based on the respondents' feedbacks, information display for level 1 are data from as built drawings if the documents drawings are available. The data displayed for Level 1 however, can be improvised in this model by including the other information according to the needs such as space code, element code, size, asset number (for $M \& E$ ), equipment brand (for $M \& E$ ), and expiry date (for $M \& E$ ). Generally, the extension on the detail's information should be displayed as Level 2. Level 2 data gathered form archived documents such as specification, contract, details drawings and manuals. Information display for level 2, the data was adopted from the data matrix (Figure 5) that contain the information on Location, dimension/asset information/capacity, specification, manufacturer, statutory, condition and cost for each of the assets and elements.

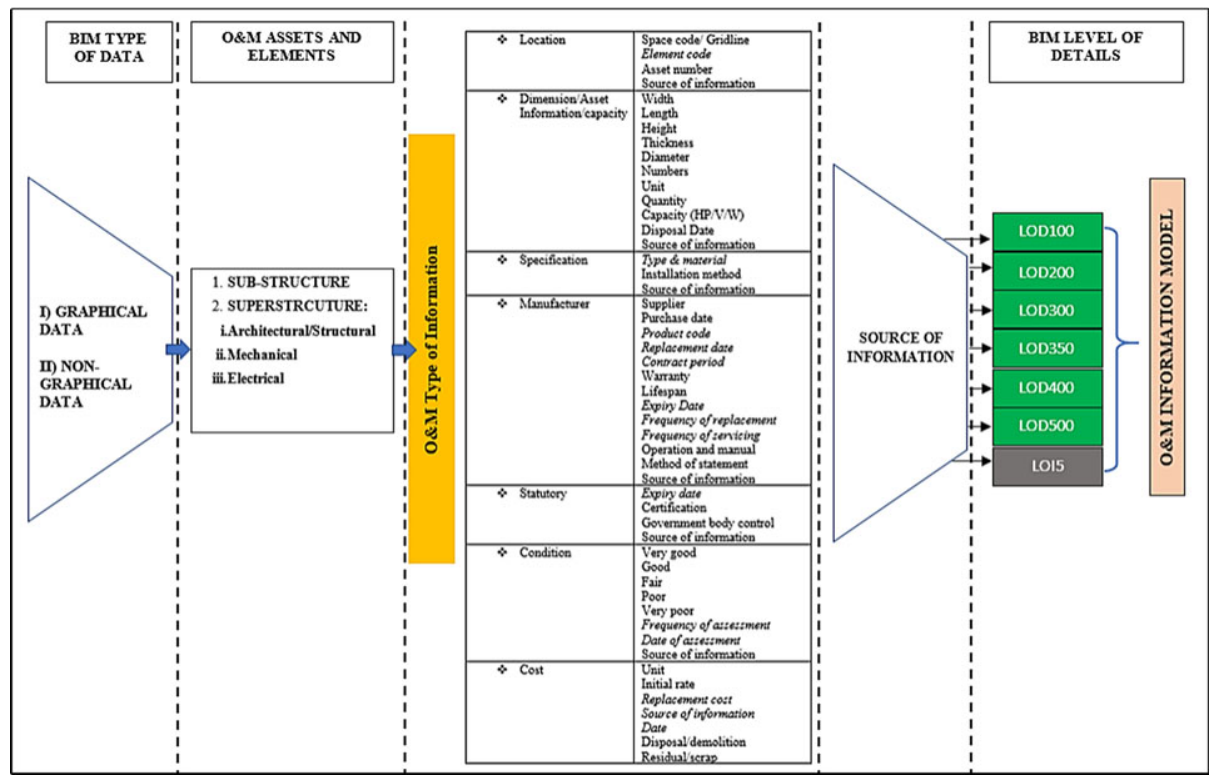

Fig. 4. Implementation framework of simplified BIM model for O\&M digital mobile application 


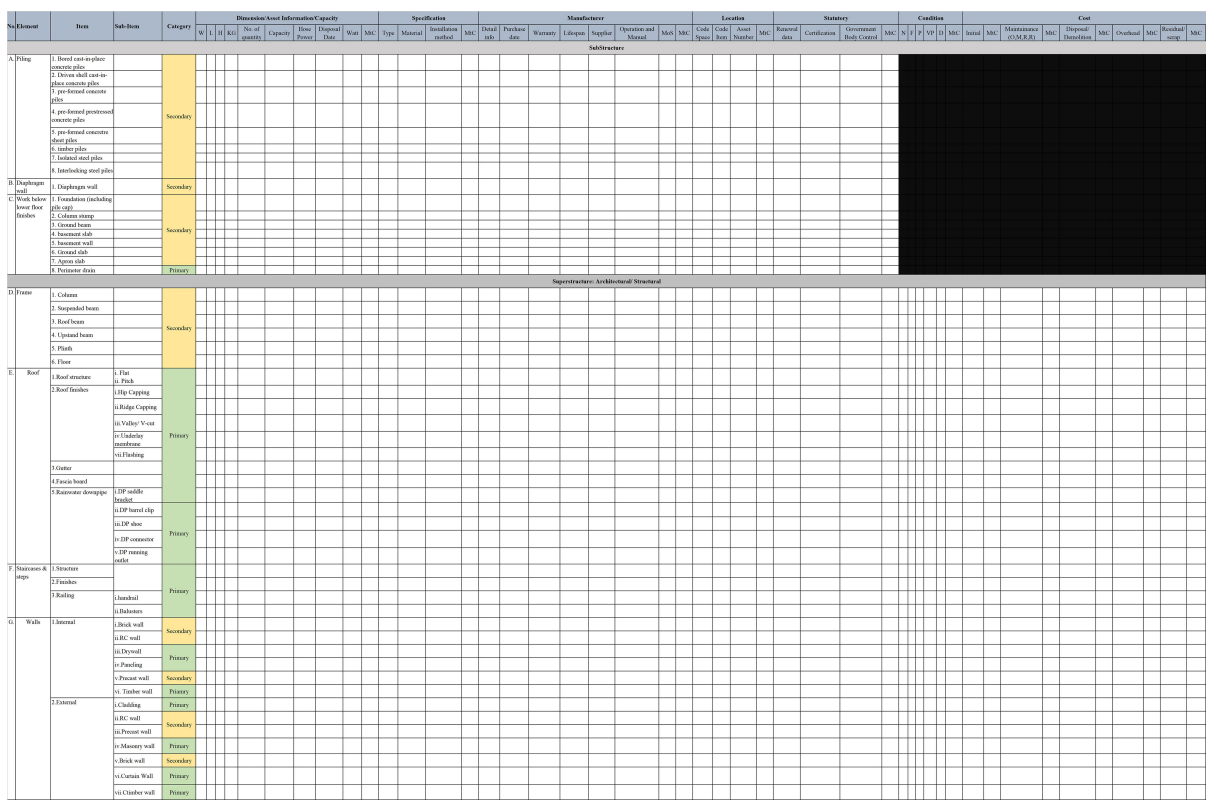

Fig. 5. Data matrix for critical information in BIM digital mobile application

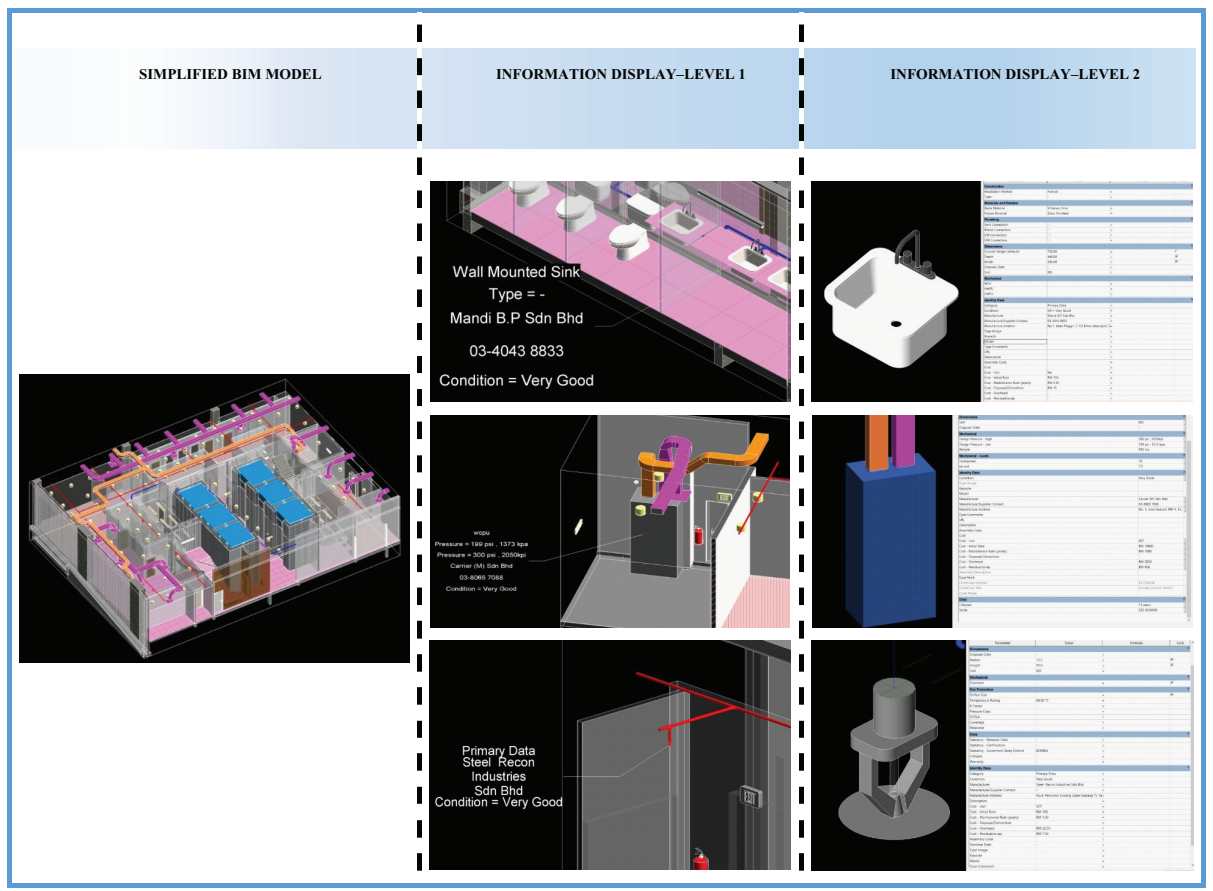

Fig. 6. Simplified BIM digital mobile application for O\&M 


\section{Conclusion}

In conclusion, the implementation of BIM within the Operation and Maintenance in Malaysia has been investigated. The information that should be prioritised to enable BIM digital mobile application at the O\&M phase has been identified. Critical information that should be prioritised based on the in-depth analysis of the literature review includes location, dimension/asset information/capacity, specification, statutory, manufacturer, condition, and cost. Critical information can be collected from various sources such as building inspection report, as-built drawings, construction drawings, purchase approval (technical material sheet and sample), contract documents, and on-site survey. A prototype for Simplified BIM Model Digital Mobile Application has been developed using REVIT software alone to digitalise all important data needed in executing O\&M tasks.

\section{$8 \quad$ References}

[1] Andreja, R. (2017). Industry 4.0 Concept: Background and Overview. International Journal Of Interactive Mobile Technologies (IJIM), 11(05), 77-90, doi: http://dx.doi.org/10.3991/ ijim.v13i02.9941

[2] Aghimien, D.O., Aigbavboa, C.O., \& Oke, A.E. (2020). Critical success factors for digital partnering of construction organisations - a Delphi study. Engineering, Construction and Architectural Management, 27(10), 3171-3188. https://doi.org/10.1108/ECAM-112019-0602

[3] Castagnino, S., Rothballer, C., \& Gerbert, P. (2016). What's the Future of the Construction Industry? World Economic Forum. Retrieved from https://www.weforum.org/ agenda/2016/04/building-in-thefourth-industrial-revolution/

[4] Nawi, M.N.M., Haron, A.T., Hamid, Z.A., Kamar, K.A.M., \& Baharuddin, Y. (2014). Improving Integrated Practice through Building Information Modeling-Integrated Project Delivery (BIM-IPD) for Malaysian Industrialised Building System (IBS) Construction Projects, Malaysia Construction Research Journal, 15(2), 29-38.

[5] Gkoumas, K. (2015). CM-An introduction to Building Information Modelling (BIM). Retrieved from https://www.slideshare.net/Kongkoumas/20151217-kg-bim

[6] Haron, N.A., Soh, R.P.Z.A.R., \& Harun, A. (2017). Implementation of building information modelling (BIM) in Malaysia: A Review. Pertanika Journal of Science and Technology, 25(3), 661-674.

[7] Kjartansdóttir, I.B., Mordue, S., Nowak, P., Philp, D., \& Snæbjörnsson, J.T. (2017). Building Information Modelling BIM. Warsaw: Civil Engineering Faculy of Warsaw University of Technology.

[8] Bortolini, R., Forcada, N., \& Macarulla, M. (2016). BIM for the integration of Building Maintenance Management: A case study of a university campus. Paper presented at the 11 th European Conference on Product \& Process Modelling, Limassol, Cyprus.

[9] Gao, X., \& Pishdad-Bozorgi, P. (2019). BIM-enabled facilities operation and maintenance: A review. Advanced Engineering Informatics, 39. https://doi.org/10.1016/i.aei.2019.01.005

[10] Ali, A.S., Chua, S.J.L., \& Ag-Ali, D.G.B. (2016). Issues and Challenges Faced by Government Office Buildings in Performing Maintenance Work. Jurnal Teknologi. 78(11), 11-23. https://doi.org/10.11113/.v78.8363

[11] AssetWorks. (2019). Infographic: The Asset Lifecycle. Retrieved from https://www.assetworks.com/resource-items/asset-lifecycle-infographic/ 
[12] Jing-Ying, W., Chun-Chieh, Y., Su-Ting, Y., Andy, C., Sien-Ti, K., Teck-Leong, L., Mohammed, T.A., \& Essameldin, G. (2020). BIM-VR Framework for Building Information Modelling in Engineering Education, International Journal Of Interactive Mobile Technologies (IJIM), 14(06), 15-39. https://doi.org/10.3991/ijim.v14i06.13397

[13] Montague, R. (2016). Building Information Modelling: What information is in the model? Retrieved from https:/www.thenbs.com/knowledge/building-informationmodelling-what-information-is-in-the-model

[14] Mordue, S. (2015). BIM Levels of Information. Retrieved from https://www.thenbs.com/ knowledge/bim-levels-of-information

[15] AIA. (2013). Guide, Instructions and Commentary to the 2013 AIA Digital Practice Documents. from American Institutes of Architects. https://oliebana.files.wordpress. com/2014/02/aiab095711.pdf

[16] Dallasega, P., Erwin, R., Dominik, T.M., \& Andrea, F. (2015). Increasing productivity in ETO construction projects through a lean methodology for demand predictability Proceedings of the 2015 International Conference on Industrial Engineering and Operations Management Dubai, United Arab Emirates (UAE), March 3-5. https://doi.org/10.1109/ IEOM.2015.7093734

[17] Kjartansdóttir, I.B., Mordue, S., Nowak, P., Philp, D., \& Snæbjörnsson, J.T. (2017). Building Information Modelling BIM. Warsaw: Civil Engineering Faculy of Warsaw University of Technology.

[18] Mayouf, M., Boyd, D., \& Cox, S. (2014). Different Perspectives on Facilities Management To Incorporate in BIM. Paper presented at the CIB Facilities Management Conference, Denmark.

[19] NBS. (n.d). What is Building Information Modelling (BIM)? Retrieved from https://www. thenbs.com/knowledge/what-is-building-information-modelling-bim

[20] Mroczkowska, A. (2021). What is a mobile App? App Development Basics for Businesses. Retrieved from https://www.thedroidsonroids.com/blog/what-is-a-mobile-app-appdevelopment-basics-for-businesses

[21] World Bank. (2021). Mobile Cellular Subscriptions. Retrieved from https://data.worldbank. org/indicator/IT.CEL.SETS?end=2019\&start=2009

[22] Norhazren, I.M., Ali, K.N., Ahmad, F.A.F., \& Shirin, S.E. (2019). Understanding the Level of Self-Directed Learning and Decision-Making Style of Construction-Related Workers", International Journal Of Interactive Mobile Technologies (IJIM), 13(07), 44-53. https://doi. org/10.3991/ijim.v13i07.10749

[23] McPartland, R. (2017). BIM Dimensions-3D, 4D, 5D, 6D BIM explained. Retrieved from https://www.thenbs.com/knowledge/bim-dimensions-3d-4d-5d-6d-bim-explained

[24] Au-Yong, C.P., Ali, A.S., \& Ahmad, F. (2014). Prediction Cost Maintenance Model of Office Building Based on Condition-Based Maintenance. Eksploatacja i Niezawodnosc, 16(2), 319-324.

[25] Institition of Surveyors Malaysia. (2010). CP BS101: Code of Practice for Building Inspection Reports: The Royal Institution of Surveyors Malaysia.

\section{Authors}

Azlan Shah Ali is a professor in the Department of Building Surveying, Faculty of Built Environment, University of Malaya, Kuala Lumpur. He was promoted to the full professor post in July 2013, which make him as one of the youngest professors in the University. Prof. Azlan completed his PhD at Universiti Teknologi MARA, Malaysia specialising in building refurbishment. His research interests lie in building 
maintenance and refurbishment with the focus to improve management strategies. He has collaborated actively with researchers in several other disciplines of built environment, particularly surveying and architecture local and internationally. Prof. Azlan has been involved in several academic research and consultations with a total amount of more than RM5 million and published over 200 peer-reviewed technical publications in journals, proceedings, and books. E-mail: asafab@um.edu.my

Norhanim Zakaria is an associate professor in the Department of Quantity Surveying, Faculty of Built Environment, University of Malaya. Previously, she worked with the building industry since 1998 and now persuading her research interest in project management focusing on Life Cycle Cost (LCC). She has worked in various research projects as a Principal Investigator and as a co-researcher for external and internal grants; and has published more than 30 articles in academic journals, including ISI and Scopus indexed, and books. She also has contributed articles in newsletters and bulletin and presented papers in conferences locally and internationally. E-mail: norhanimz@, um.edu.my

Umi Kalsum Zolkafli@Zulkifly holds a doctoral degree in Built Environment from the Universiti Teknologi Mara, Malaysia in the year 2017 and is now persuading her research interest in construction contract management and professional practice fields. Prior to that, she worked with the industry for 10 years as a Quantity Surveyor and Management Representatives at ARR QS Consultancy. Dr.Umi Kalsum registered as Consultant Quantity Surveyors (CQS) under the Board of Surveyors Malaysia (BQSM) and a Fellow of The Royal Institution of Surveyors Malaysia (FRISM). She actively involved with BQSM and RISM as an organizing committee for several international conferences, seminars and workshop. E-mail: umi@um.edu.my

Article submitted 2021-04-27. Resubmitted 2021-06-15. Final acceptance 2021-06-15. Final version published as submitted by the authors. 